\title{
ĐIỀU TRI NGOẠI KHOA HẸP ĐỘNG MẠCH CẢNH NGOÀI SỌ BẰG KỸ THUẬT LộT NGƯợC NỘI MẠC VỚI GÂY TÊ TẠI CHỖ
}

\author{
Nguyễn Văn Quảng *, Dương Đinh Bảo *, Phạm Minh Ánh*
}

\section{TÓM TÁT}

Chúng tôi đã thực hiện 75 trường hợp bóc nội mạc động mạch cảnh trong kiểu lột ngược với gây tê tại chỗ. Tuổi trung bình là $62,6 \pm 4,0$, tỷ lệ nam/nữ là $4,76: 1$. Có 60 trường hợp $(80 \%)$ hẹp động mạch cảnh có triệu chứng, 12 trường hợp $(16 \%)$ có hẹp cả hai bên. Tất cả các trường hợp đều cải thiện triệu chứng lâm sàng sau mồ. 5 trường hợp $(6,7 \%)$ có biến chứng đột quỵ sau mổ có hồi phục, 4 trường hợp $(5,3 \%)$ chảy máu sau mổ phải mổ lại cầm máu; 10 trường hợp $(13,3 \%)$ tụ máu vết mổ (khỏi sau điều trị nội khoa, không mổ lại); 4 trường hợp khàn tiếng $(5,3 \%)$. Theo dõi từ 6 tháng - 36 tháng, tất cả các bệnh nhân đều hết triệu chứng lâm sàng, có 2 trường hợp $(2,7 \%)$ tái hẹp. Phẫu thuật bóc nội mạc động mạch cảnh trong kiểu lột ngược là phương pháp điều trị hiệu quả và an toàn cho hẹp động mạch cảnh ngoài sọ.

Từ khóa: Hẹp động mạch cảnh ngoài sọ, nhồi máu não, bóc nội mạc động mạch cảnh trong kiểu lột ngược.

\section{SUMMARY}

\section{SURGICAL TREATMENT OF} \section{EXTRACRANIAL CAROTID STENOSIS BY} EVERSION TECHNIQUE WITH LOCAL \section{ANESTHESIA}

75 eversion carotid endarterectomy were performed with mean age $62,6 \pm 4,0$, ratio male:female was 4,76:1. There were 60 symptomatic cases $(80 \%), 12$ cases $(16 \%)$ with bilateral carotid stenosis. We used eversion technique in all cases with local anesthesia. The rate of postoperative stroke was $6,7 \%$ (5 cases). Other complications were 4 cases $(5,3 \%)$ of bleeding (must re-operate to treat), 10 cases $(13,3 \%)$ of wound hematoma (just use medical therapy), 4 cases $(5,3 \%)$ of hoarseness. All cases were in good condition after 6-36 months followup, 2 cases $(2,7 \%)$ appeared with recurrent stenosis. Eversion carotid endarterectomy is considered as a safe and effective methods for treatment of ECAS.

Key words: Extracranial Carotid stenosis, Stroke, Eversion carotid endarterectomy

\section{I. ĐẠT VẤN ĐỀ}

Nhồi máu não chiếm $80 \%$ các trường hợp tai biến mạch máu não (TBMMN), trong đó nguyên nhân do hẹp động mạch cảnh là 15-30\%. Tại Hoa Kỳ khoảng 730.000 trường hợp bị TBMMN mỗi năm và chi phí điều trị, chăm sóc cho các bệnh nhân này lên đến 40 tỷ đô la. Phẫu thuật bóc nội mạc động mạch cảnh nhằm mục đích làm giảm nguy cơ nhồi máu não. Hiệu quả của phẫu thuật này đã được chứng minh từ nhiều năm nay trên thế giới $[8,12]$. Có nhiều kỹ thuật mổ, bao gồm: bóc nội mạc động mạch cảnh và phục hồi động mạch cảnh trực tiếp hoặc có miếng vá mạch máu nhân tạo hoặc bóc nội mạc động mạch cảnh kiểu lột ngược. Ngày nay, mặc dù có sự phát triển mạnh mẽ của can thiệp nội mạch trong điều trị các bệnh lý tắc hẹp động mạch, nhưng phẫu thuật bóc nội mạch động mạch cảnh vẫn là phương pháp điều trị được chọn lựa trong hẹp động mạch cảnh ngoài sọ [16].

Nghiên cứu của chúng tôi nhằm đánh giá hiệu quả của phẫu thuật bóc nội mạc động mạch cảnh trong kiểu lột ngược trong việc phòng ngừa đột quỵ não trên bệnh nhân có hẹp động mạch cảnh ngoài sọ.

\footnotetext{
* Khoa Phẫu thuật Mạch máu Bệnh viện Chơ Rã̃y Ngưòi chịu trách nhiệm khoa học: ThS. Nguyễn Văn Quảng Ngày nhận bài: 01/05/2018 - Ngày Cho Phép Đăng: 20/05/2018 Phản Biện Khoa học: GS.TS. Bùi Đức Phú PGS.TS. Đặng Ngọc Hùng
} 


\section{II. ĐỐI TƯợNG VÀ PHƯONG PHÁP NGHIÊN CÚ'U}

Hồi cứu, mô tả hàng loạt trường hợp hẹp động mạch cảnh trong được phẫu thuật bóc nội mạc kiểu lột ngược với gây tê tại chỗ tại khoa Phẫu thuật Mạch máu bệnh viện Chợ Rẫy từ 01/03/2012 đến 31/12/2017. Phân tích các đặc điểm về lâm sàng, các yếu tố nguy cơ và bệnh kết hợp, đánh giá mức độ hẹp theo tiêu chuẩn Bắc Mỹ (NASCET) dựa trên siêu âm Doppler và chụp cắt lớp điện toán dựng hình hệ động mạch cảnh. Chỉ định phẫu thuật cho hẹp động mạch cảnh trong từ $70-99 \%$, có hoặc không triệu chứng. Kỹ thuật mổ là bóc nội mạc động mạch cảnh kiểu lột ngược. Đánh giá kết quả sớm trong vòng 30 ngày sau mổ dựa trên lâm sàng và siêu âm Doppler động mạch cảnh, theo dõi bệnh nhân từ 6 tháng đến 36 tháng. Tái hẹp được định nghĩa khi hẹp trên $50 \%$ sau mổ. Kết quả tốt khi bệnh nhân cải thiện triệu chứng lâm sàng, không có biến chứng nghiêm trọng như đột quy, tử vong, không tái hẹp; trung bình khi có biến chứng khắc phục được, tái hẹp nhưng không có đột quỵ tiến triển hoặc tử vong; xấu khi có đột quỵ tiến triển, tử vong.

\section{KẾT QUẢ}

Trong thời gian từ $01 / 03 / 2012$ đến 31/12/2017, có 75 bệnh nhân hẹp động mạch cảnh được điều trị phẫu thuật bóc nội mạc động mạch cảnh trong kiểu lột ngược tại khoa Phẫu thuật Mạch máu, bệnh viện Chợ Rẫy. Các bệnh nhân trong nghiên cứu của chúng tôi có tuổi trung bình là $62,6 \pm 4,0$; trong đó nam giới chiếm $82,6 \%$ (62 trường hợp), với các đặc điểm lâm sàng như sau:

Bảng 3.1. Đặc điểm bệnh nhân nhóm nghiên cứu

\begin{tabular}{|l|c|c|}
\hline \multicolumn{1}{|c|}{ Đặc điểm lâm sàng } & $\begin{array}{c}\text { Số bệnh nhân } \\
(\mathrm{n}=75)\end{array}$ & $\begin{array}{c}\text { Tỷ lệ } \\
(\%)\end{array}$ \\
\hline - Có triệu chứng & 60 & 80 \\
- Không triệu chứng & 15 & 20 \\
\hline $\begin{array}{l}\text { Phẫu thuật sớm (< 2 } \\
\text { tuần) sau đột quỵ thiếu } \\
\text { máu não }\end{array}$ & 9 & 12 \\
\hline
\end{tabular}

\begin{tabular}{|l|c|c|}
\hline $\begin{array}{l}\text { Các yếu tố nguy cơ, } \\
\text { bệnh kết hợp }\end{array}$ & \multicolumn{2}{|c|}{} \\
\hline Hút thuốc lá & 58 & 77 \\
Tăng huyết áp & 70 & 93 \\
Đái tháo đường & 15 & 20 \\
Rối loạn lipid máu & 69 & 92 \\
Bệnh mạch vành & 9 & 12 \\
Bệnh mạch máu & 25 & 33 \\
ngoại biên & & \\
\hline
\end{tabular}

Bảng 3.2. Sử dụng shunt tạm

\begin{tabular}{|l|c|c|}
\hline \multicolumn{1}{|c|}{ Shunt tạm } & $\begin{array}{c}\text { Số bệnh nhân } \\
(\mathrm{n}=75)\end{array}$ & Tỷ lệ (\%) \\
\hline Có đặt shunt tạm & 26 & 35 \\
\hline Không đặt shunt tạm & 49 & 65 \\
\hline
\end{tabular}

Biến chứng sớm sau mổ (30 ngày): không có trường hợp tử vong sau mổ; có 5 trường hợp đột quỵ thiếu máu não sau mổ trong 24 giờ đầu, sau 24 - 48 giờ hồi phục dần, không có hình ảnh tổn thương não trên phim chụp cắt lớp, không để lại di chứng; có 4 trường hợp chảy máu sau mổ phải mổ lại cầm máu; 10 trường hợp tụ máu vết mổ (khỏi sau điều trị nội khoa, không mổ lại); 4 trường hợp khàn tiếng.

Bảng 3.3. Biến chứng sớm sau mổ (30 ngày )

\begin{tabular}{|l|c|c|}
\hline \multicolumn{1}{|c|}{ Biến chứng } & $\begin{array}{c}\text { Số trường } \\
\text { hợp }(\mathrm{n}=75)\end{array}$ & $\begin{array}{c}\text { Tỷ lệ } \\
(\%)\end{array}$ \\
\hline $\begin{array}{l}\text { Đột quỵ thoáng qua (có } \\
\text { hồi phục) }\end{array}$ & 5 & 6,7 \\
$\begin{array}{l}\text { Chảy máu sau mồ (phải } \\
\text { mồ cầm máu) }\end{array}$ & 4 & 5,3 \\
$\begin{array}{l}\text { Khàn tiếng } \\
\text { Tụ máu vết mổ }\end{array}$ & 4 & 5,3 \\
$\begin{array}{l}\text { Tử vong } \\
\text { Biến chứng khác }\end{array}$ & 0 & 13,3 \\
\end{tabular}

Kết quả điều trị theo dõi từ $6-36$ tháng cho thấy có 2 trường hợp $(2,7 \%)$ tái hẹp.

Bảng 3.4. Kết quả theo dõi từ $6-36$ tháng

\begin{tabular}{|l|c|c|}
\hline Kết quả & $\begin{array}{c}\text { Số trường } \\
\text { hợp }(\mathrm{n}=75)\end{array}$ & Tỷ lệ $(\%)$ \\
\hline Tốt & 69 & 92 \\
Trung bình & 6 & 8 \\
Xấu & 0 & 0 \\
\hline
\end{tabular}




\section{BÀN LUẬn}

Hiện nay, mặc dù có sự phát triển mạnh mẽ của can thiệp nội mạch, tuy nhiên phẫu thuật bóc nội mạc động mạch cảnh vẫn còn là phương pháp điều trị hiệu quả hẹp động mạch cảnh ngoài sọ do xơ vữa $[10,11]$.

Hẹp động mạch cảnh ngoài sọ là nguyên nhân chính gây ra cơn thiếu máu não cục bộ và nhồi máu não. Việc phát hiện sớm và điều trị thích hợp sẽ giúp bệnh nhân giảm nguy cơ nhồi máu não cũng như các hậu quả nặng nề sau đó. Phẫu thuật bóc nội mạc động mạch cảnh ở bệnh nhân chưa đột quỵ sẽ làm giảm nguy cơ đột quỵ và tàn phế cho bệnh nhân.

Hẹp động mạch cảnh thường thấy ở bệnh nhân nam, lớn tuổi. Trong nghiên cứu của chúng tôi tuổi trung bình của bệnh nhân là $62,6 \pm 4,0$, tỷ lệ nam/nữ là $4,76 / 1$. Điều này cũng tương tự các nghiên cứu khác trong và ngoài nước $[0,4]$.

Siêu âm Doppler là phương pháp chẩn đoán hình ảnh rất có giá trị trong chẩn đoán hẹp động mạch cảnh. Tất cả các trường hợp hẹp động mạch cảnh trong nghiên cứu của chúng tôi đều được làm siêu âm Doppler động mạch cảnh và động mạch đốt sống. Tuy nhiên độ nhạy và độ chuyên biệt của phương pháp này tùy thuộc rất nhiều vào tay nghề của bác sĩ siêu âm. Ngoài ra siêu âm còn có vai trò rất lớn trong tầm soát bệnh lý động mạch cảnh trên các đối tượng bệnh nhân nguy cơ cao như: giới nam, trên 50 tuổi, hút thuốc lá, tăng huyết áp, đái tháo đường, rối loạn mỡ máu.

Chụp cắt lớp điện toán đa lát cắt dựng hình hệ động mạch cảnh (MSCT) là một phương pháp chẩn đoán hình ảnh không xâm lấn có độ nhạy và độ đặc hiệu cao, có thể thay thế chụp mạch máu xoá nền, đặc biệt giúp đánh giá vòng nối động mạch trong sọ. Chúng tôi chỉ định chụp cắt lớp điện toán cho tất cả các trường hợp $(100 \%)$ và chỉ định phẫu thuật dựa trên mức độ hẹp trên MSCT đo theo tiêu chuẩn Bắc Mỹ (NASCET) [8]
Chỉ định phẫu thuật bóc nội mạc động mạch cảnh được Hội tim mạch Hoa Kỳ [Error! Reference source not found.,10] khuyến cáo khi hẹp trên $50 \%$ có triệu chứng và hẹp trên $60 \%$ không triệu chứng, đặc biệt có hiệu quả rõ rệt khi hẹp từ $70-99 \%$. Trong nghiên cứu của chúng tôi, số lượng bệnh nhân có triệu chứng còn cao ( $80 \%$ trường hợp). Qua đó cho thấy cần chú ý hơn nữa tầm soát bệnh lý động mạch cảnh để điều trị sớm hơn cho bệnh nhân vì đây là phẫu thuật có ý nghĩa dự phòng nhằm phòng ngừa đột quỵ cho bệnh nhân có hẹp động mạch cảnh.

Đối với các trường hợp bệnh nhân đã có nhồi máu não do hẹp động mạch cảnh thì chỉ định phẫu thuật nhằm làm giảm nguy cơ đột quỵ tái phát. Cho đến nay, thời điểm phẫu thuật sau đột quỵ được đa số các tác giả thống nhất là 2 tuần $[7,9,14]$. Tuy nhiên một số nghiên cứu gần đây cho thấy phẫu thuật sớm ở những trường hợp có hồi phục tốt trong vòng 1 tuần không làm tăng tỉ lệ tử vong và biến chứng nhưng giảm được nguy cơ nhồi máu não tái phát và tỷ lệ tử vong cho bệnh nhân [14]. Trong nghiên cứu của chúng tôi có 5 trường hợp được phẫu thuật sớm sau nhồi náu não 2 tuần, cả 5 trường hợp đều có kết quả sau mổ tốt.

Phẫu thuật bóc nội mạc động mạch cảnh nhằm mục đích dự phòng đột quỵ thiếu máu não, tránh được tử vong và tàn phế cho bệnh nhân. Tuy nhiên chính phẫu thuật cũng có thể gây ra biến chứng đột quỵ. Do đó, việc phòng tránh biến chứng đột quỵ là rất cần thiết và có ý nghĩa quyết định trong thành công của cuộc mổ.

Việc sử dụng shunt tạm thường quy hay có chọn lọc vẫn còn là vấn đề bàn cãi. Tuy nhiên trong đa số nghiên cứu trong $\mathrm{y}$ văn cho thấy sử dụng shunt chọn lọc được đa số phẫu thuật viên chấp nhận $[2,3,6]$.

Chỉ định đặt shunt tạm khi mổ bóc nội mạc động mạch cảnh trong nghiên cứu của chúng tôi cho các trường hợp sau: tắc hoặc hẹp nặng động mạch cảnh trong bên đối diện, bệnh nhân có 
tiền sử nhồi máu não hoặc đột quỵ thiếu máu não dưới 2 tuần, có kèm tắc hẹp động mạch đốt sống và chỉ định bắt buộc khi có triệu chứng thần kinh sau khi kẹp động mạch cảnh trong với mổ gây tê tại chỗ.

Về phương pháp vô cảm, nghiên cứu GALA (2008) [12] cho thấy không có sự khác biệt có ý nghĩa về tỷ lệ tử vong và biến chứng khi mổ với gây tê hoặc gây mê. Lựa chọn phương pháp vô cảm tuỳ theo phẫu thuật viên.

Chúng tôi chọn lựa phương pháp gây tê tại chỗ cho tất cả các trường hợp nhằm đánh giá khả năng thích ứng của bệnh nhân khi kẹp động mạch cảnh để chỉ định sử dụng shunt tạm. Sau khi kẹp động mạch cảnh trong, nếu bệnh nhân xuất hiện các triệu chứng thần kinh như giảm hoặc mất tri giác, giảm hoặc mất vận động chi đối bên thì chúng tôi chỉ định sử dụng shunt tạm. Theo Calligaro and Dougherty [5] nghiên cứu mối tương quan giữa áp lực động mạch cảnh bít với thay đổi về mặt thần kinh trên 474 bệnh nhân phẫu thuật động mạch cảnh với gây tê tại chỗ cho thấy áp lực động mạch cảnh bít dưới $40 \mathrm{mmHg}$ là ngưỡng để chỉ định sử dụng shunt tạm.

Bóc nội mạc động mạch cảnh kiểu lột ngược (Eversion technique) là phương pháp hiện đại ngày càng được sử dụng rộng rãi trên thế giới với nhiều ưu việt so với phương pháp kinh điển xẻ dọc động mạch cảnh bóc nội mạc sau đó phục hồi bằng cách khâu trực tiếp nếu đường kính lòng mạch đủ lớn hoặc tạo hình bằng miếng vá mạch cảnh nhân tạo. Các nghiên cứu cho thấy Eversion có tỷ lệ tái hẹp thấp hơn có ý nghĩa so với kỹ thuật kinh điển sử dụng miếng vá $[13,15,16]$. Giai đoạn gần đây chúng tôi sử dụng kỹ thuật này này càng nhiều hơn.

Kết quả theo dõi bước đầu cho thấy hiệu quả tốt của phẫu thuật trong việc cải thiện tình trạng thiếu máu não qua lâm sàng và siêu âm Doppler hệ động mạch cảnh. Trong nghiên cứu này chỉ có 2 trường hợp tái hẹp (hẹp trên $50 \%$ ), tuy nhiên không có trường hợp nào nhồi máu não mới cũng như tái phát.

\section{KẾT LUẬN}

Hẹp động mạch cảnh thường xảy ra ở bệnh nhân nam, lớn tuổi. Chẩn đoán chủ yếu dựa trên siêu âm Doppler mạch máu. Chụp cắt lớp điện toán dựng hình hệ động mạch cảnh là cần thiết cho chỉ định điều trị ngoại khoa. Phẫu thuật bóc nội mạc động mạch cảnh trong bằng phương pháp lột ngược có thể mổ gây tê tại chỗ, là phương pháp điều trị hiệu quả và an toàn cho hẹp động mạch cảnh ngoài sọ do xơ vữa.

\section{TÀI LIỆU THAM KHẢO}

1. Đỗ Kim Quế (2011), "Vai trò của phẫu thuật bóc lớp trong động mạch cảnh trong phòng ngừa đột quỵ não", Y Học TP. Hồ Chí Minh, Tập 15, Phụ bản của Số 2, tr. 237 -242

2. Ali F. AbuRahma, MD, Albeir Y. Mousa, MD, and Patrick A. Stone (2011), "Shunting during carotid endarterectomy", J Vasc Surg;54: p.1502-10

3. Ali F. AbuRahma, Patrick A. Stone, Stephen M. Hass (2010), "Prospective randomized trial of routine versus selective shunting in carotid endarterectomy based on stump pressure", J Vasc Surg; 51: p. 1133-8

4. C.N. Antonopoulos, J.D. Kakisis, T.N. Sergentanis, C.D. Liapis (2011), "Eversion versus Conventional Carotid Endarterectomy: A Meta-analysis of Randomised and Non-randomised Studies" Eur J Vasc Endovasc Surg, 42, p.751 - 765

5. Calligaro K. D and Dougherty M. J (2005), "Correlation of carotid artery stump pressure and neurologic changes during 474 carotid endarterectomies performed in awake 
patients", J Vasc Surg; 42: p. 684-9

6. Enzo Ballotta and Giuseppe Da Giau (2003), "Selective shunting with eversion carotid endarterectomy", J Vasc Surg ;38, p.1045-50

7. Enzo Ballotta, Giorgio Meneghetti, Giuseppe Da Giau, Renzo Manara, Marina Saladini, $\mathrm{MD},{ }^{\mathrm{b}}$ and Claudio Baracchini (2008), "Carotid endarterectomy within 2 weeks of minor ischemic stroke: A prospective study" , J Vasc Surg; 48: p. 595-600

8. Gary G. Ferguson, Michael Eliasziw, Hugh W.K. Barr, G. Patrick Clagett, Robert W. Barnes, MD, M. Christopher Wallace (1999), "The North American Symptomatic Carotid Endarterectomy Trial Surgical Results in 1415 Patients", Stroke; 30:p.1751-175

9. Guy Leseche, Jean-Marc Alsac, Rabih Houbbalah, Yves Castier, Francis Fady, Mikael Mazighi, and Pierre Amarenco (2010) , "Carotid endarterectomy in the acute phase of stroke-in-evolution is safe and effective in selected patients

10. John J. Ricotta, Ali AbuRahma, Enrico Ascher, Mark Eskandari (2011), "Updated Society for Vascular Surgery guidelines for management of extracranial carotid disease", J Vasc Surg; 54: p. 1 - 31

11. Kenneth Rosenfield, Jon S. Matsumura, Seemant Chaturvedi, Tom Riles, Gary M. Ansel, Chris Metzger, Lawrence Wechsler, Michael R. Jaff (2016), "Randomized Trial of Stent versus Surgery for Asymptomatic Carotid Stenosis", The new England journal of medicine, vol. 374 no. 11, p. $1011-1020$

12. Lewis S. C, Warlow C P, Bodenham A R,
Colam B, Rothwell P M, Torgerson D, Dellagrammaticas D (2008), "General anaesthesia versus local anaesthesia for carotid surgery (GALA): a multicentre, randomised controlled trial", Lancet; 372: p. 2132-42

13. P. Cao, P. De Rango and S. Zannetti (2002), "Eversion vs Conventional Carotid Endarterectomy: a Systematic Review", Eur J Vasc Endovasc Surg, 23, p.195-201

14. Rantner B, Schmidauer C, Knoflach M, Fraedrich G (2015), "Very Urgent Carotid Endarterectomy Does Not Increase the Procedural Risk", Eur J Vasc Endovasc Surg, 49, p. $129-136$

15. Serdar Demirel, MD; Nicolas Attigah, MD; Hans Bruijnen, MD; Peter Ringleb, PhD; Hans-Henning Eckstein, PhD; Gustav Fraedrich (2012), "Multicenter Experience on Eversion Versus Conventional Carotid Endarterectomy in Symptomatic Carotid Artery Stenosis", Stroke.;43:p.1865-1871

16. Tony Katras, Ulises Baltazar, Daniel S. Rush, W. Chris Sutterfield, Leo M. Harvill, , and Paul E. Stanton (2001), "Durability of eversion carotid endarterectomy: Comparison with primary closure and carotid patch angioplasty", J Vasc Surg; 34:p453-8 